\title{
Blockchain and mortgage lending process: A study of people, process, and technology involved
}

\author{
Azad I. Ali, Indiana University of Pennsylvania, USA, azad.ali@iup.edu \\ David T. Smith, Indiana University of Pennsylvania, USA, david.smith@iup.edu
}

\begin{abstract}
Blockchain technology is on the rise and considered to be a revolutionary technology. It has been applied to many domains including personal health records, regulatory investigation, and global supply chain. Applications that may potentially benefit from blockchain technology are those, which involve multiple parties across the different organization, each performing a subset of many steps needed to complete a given transaction and involve different technologies. In addition, security and trust is a major concern. Given this, a good candidate for blockchain technology is mortgage lending. The purpose of this paper is to prepare a model that identifies different elements that are needed when applying blockchain technology in the mortgage origination process. This paper uses a popular framework used in customer relationship management (CRM) that combines three constructs: People, Process and Technology to develop the intended model.
\end{abstract}

Keywords: Blockchain, mortgage origination, Digital Ledger Transaction (DLT).

\section{Introduction}

During the past few years, a new technology - blockchain - has developed which is expected to replace many current digital platforms. It first came to light in the late 2000's as the architecture for bitcoin, the best known virtual currency. But, as with the Internet, the Web and other major technologies, the blockchain technology (BT) has now transcended its original objective. (de la Rosa et al, 2017, p. 1)

The testimony quoted above speaks to the revolutionary potential that blockchain may have on digital platforms. Indeed, references are abundant about this positive impact of blockchain on many digital platforms, such that some called it "Disruptive Technology" (Nofer, Gomber, Hinz, Schiereck, 2017), or "Disruptive Power" (Porru, Pinna, Marchesi, \& Tonelli, 2017). Others called it "The Internet of Value" (Tapscott, 2018), while a third group called it the "Blockchain Revolution" (Tapscott \& Tapscott, 2016). As such, use of blockchain technology has transcended its initial application into a wide variety of domains including:

- Personal health record implementation (Roehrs et al., 2018)

- Global maritime logistics (Shirani, 2018)

- Digital crime prevention (Smith \& Dhillon, 2017) 
- Smart energy grid-based application (Pieroni, Scarpato, Di Nunzio, Fallucchi, \& Raso, 2018)

- The R3 blockchain for financial institutions (Fanning \& Centers, 2016)

- Higher education (Tapscott \& Tapscott, 2017b)

- Regulatory investigation (Rennock, Cohn, \& Butcher, 2018)

- Global supply chain (Biggs, Hinish, Natale, \& Patronick, 2018)

Why and where to use blockchain technology? The answer to this question is nicely expressed by Brodersen et al. (2016):

A blockchain allows a system of independent actors to share a record of digital assets, transactions and information without the need for a central, trusted third party. It enables users to replace certain inefficient intermediary functions in different economic, social and technological systems with decentralized digital networks. (p. 3)

From scoping review of literature, researchers have outlined these conditions for a given application to be well suited to use blockchains:

- Application involves transactions which have multiple stakeholders (parties) in different organizations (de la Rosa et al., 2017)

- Data involved in a transaction is distributed across the multiple parties (Baliga, 2017; Roehrs et al., 2018)

- The transactions are decentralized, yet permit instant feedback (de la Rosa et al., 2017)

- The application requires strong levels of trust among the parties involved in a given transaction (Rennock et al., 2018)

With these conditions in mind, an application that may greatly benefit from blockchain technology is Mortgage Lending, as it:

- Involves multiple stakeholders across diverse organizations in their transactions (Renuart, 2004)

- Goes through multiple processes that are distributed across multiple parties (e.g., submitting application, appraisal, insurance, \& others) (Hutchison, 2012)

- Involves decentralized transactions that often require instant feedback (Blockchain Technology Lab, 2018)

- Mortgage loan application has transactions requiring a high level of trust among of each of its processes (Blockchain Technology Lab, 2018)

This paper explores the use of blockchain technology in mortgage lending applications. It sheds the light on from three constructs: the people, the process and the technological steps involved in applying blockchain for mortgage lending application.

\section{Research Question:}

The research question that this study answers is:

RQ: What are the organizational framework elements that are involved in applying blockchain architecture to mortgage lending applications? 


\section{Organization of This Study}

The remainder of this study is divided into the following sections:

- The conceptual framework from which a mortgage lending application will be examined.

- A literature review of blockchain technology which will outline the technical components involved.

- A literature review of mortgage lending application which will outline the steps involved and the parties affiliated with mortgage lending origination process.

- A discussion of applying blockchains to the mortgage lending application highlighting various issues involved.

- A conclusion as to the feasibility and resulting benefit of using blockchain technology in the domain of mortgage lending origination.

\section{Conceptual Framework}

The intent of this paper is to develop a model that lists the organization's elements that are required to apply blockchain technology for mortgage lending application. To achieve this objective, this paper proposes the Customer Relationship Management (CRM) framework that is commonly used in business to view a problem from three constructs: people, process and technology. The following best describes this framework:

Customer relationship management (CRM) is a combination of people, processes and technology that seeks to understand a company's customers. It is an integrated approach to managing relationships by focusing on customer retention and relationship development. CRM has evolved from advances in information technology and organizational changes in customer-centric processes. (Chen \& Popovich, 2003, p. 672)

In its simplest form, this framework can be illustrated in Figure 1.

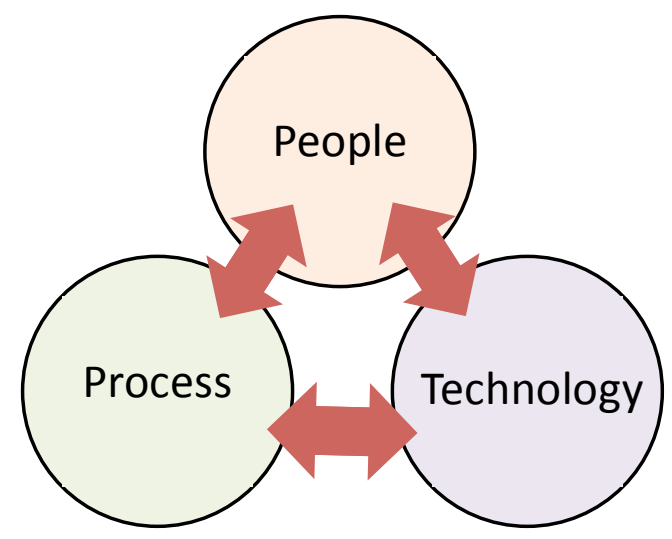

Figure 1. Customer Relation Management (CRM) Framework 
However, this simple form gets more involved when discussing the different constructs with respect to the number of parties and their roles in completing the business at the task, the number of steps involved, and the number of technologies used. The people construct identifies all the people that are involved in the completion of a given activity. This may include people from within one organization and it can include people external to the organization and in fact many people from different organizations. Here, the process construct is the steps and the procedures needed to be followed in completing a given transaction. The steps need not be restricted to boundaries within one organization, but rather may extend beyond one organization to possibly many. The technology construct of the CRM model refers to all the technologies used by the those involved in carrying out the steps. This mostly refers to technological transactions or what could it mean in terms of changes in the technology that pertain to a given transaction. Thus, the completed model in this paper refers to a number of people, each performing some subset of the steps in involved, using a variety of technologies in order to complete a given transaction. Figure 2 shows a depiction of the completed model in this paper.

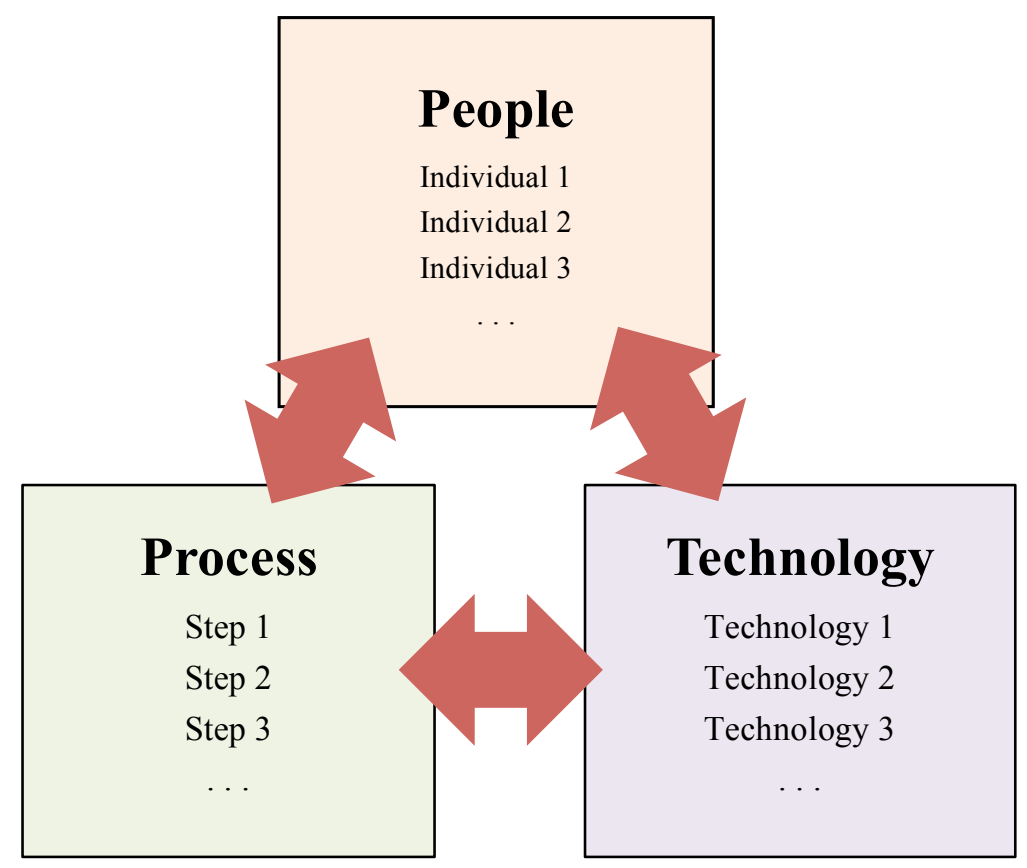

Figure 2. Suggested Organizational Framework for Blockchain

\section{Scoping Literature Review - Blockchain}

This section reviews literature about blockchain, the meaning of it, and other related information that aims at explaining what technologies are involved in blockchain. Blockchain technology is a new technology and a lot of the terms associated with are still being learned. Thus, a literature review will be helpful in explaining about it. The section starts by giving different definitions for the term blockchain. It then moves on to described different terms associated with blockchain to further clarify the framework of the technology. 


\section{Blockchain Definitions}

The definitions for blockchain range from simple to extensive. Some take it from single perspective while others explain from multiple points of views. To summarize and provide a holistic picture of blockchain, we list in Table 1 four main definitions we have found through our scoping literature review.

Table 1. Blockchain Definitions Found in the Literature

\begin{tabular}{|l|l|}
\hline \multicolumn{1}{|c|}{ Source } & \multicolumn{1}{c|}{ Definition } \\
\hline $\begin{array}{l}\text { Brodersen et al., } \\
2016\end{array}$ & $\begin{array}{l}\text { "A distributed tamperproof database that secures all records that are } \\
\text { added to it, wherever they exist" (p. 2) }\end{array}$ \\
\hline Baliga, 2017 & $\begin{array}{l}\text { Blockchain technology enables participants to read from and update to } \\
\text { a commonly shared ledger (or blockchain) whose state is collectively } \\
\text { maintained by the network in a decentralized fashion. The blockchain is } \\
\text { updated via the consensus protocol that ensures a common, } \\
\text { unambiguous ordering of transactions and blocks and guarantees the } \\
\text { integrity and consistency of the blockchain across geographically } \\
\text { distributed nodes. (p. 3) }\end{array}$ \\
\hline Tapscott, 2018 & $\begin{array}{l}\text { The blockchain is an incorruptible digital ledger of economic } \\
\text { transactions that can be programmed to record not just financial } \\
\text { transactions but virtually everything of value. Each unit of value is } \\
\text { represented by transactions recorded in a blockchain which leverages } \\
\text { the resources of a large peer-to-peer network to verify and approve } \\
\text { each transaction. (p. 3) }\end{array}$ \\
\hline $\begin{array}{l}\text { Crosby, Nachiappan, } \\
\text { Pattanayak, Verma, } \\
\text { Kalyanaraman, 2016 }\end{array}$ & $\begin{array}{l}\text { A blockchain is essentially a distributed database of records or public } \\
\text { ledger of all transactions or digital events that have been executed and } \\
\text { shared among participating parties. Each transaction in the public } \\
\text { ledger is verified by consensus of a majority of the participants in the } \\
\text { system. Once entered, information can never be erased. The blockchain } \\
\text { contains a certain and verifiable record of every single transaction ever } \\
\text { made. (p. 8) }\end{array}$ \\
\hline
\end{tabular}

The definitions listed in Table 1 include terms and concepts that need to be clarified in order to better understand blockchain. The remainder of this section explains the following terms that are related to blockchain:

- Digital ledger transaction

- Interoperability

- The block

- The chain

- Public and private keys

- Digital signature

- Consensus model 


\section{Digital Ledger Transaction}

Rennock et al. (2018) noted that a Digital Ledger Transaction (DLT) is the foundation of blockchain and define it as:

DLT offers a consensus validation mechanism through a network of computers that facilitates peer-to-peer transactions without the need for an intermediary or a centralized authority to update and maintain the information generated by the transactions. Each transaction is validated and, along with a group of validated transactions, is added as a new "block" to an already existing chain of transactions, giving rise to the name "blockchain." Once a transaction has been added to the chain, it generally cannot be altered or removed. (p. 36)

The DLT is the essence of the blockchain, it starts the process and all related transactions are recorded in the DLT. A ledger is often referenced in financial transactions to mean a book that records transactions financial or otherwise (Hutchison, 2012; Tapscott \& Tapscott, 2017a). Companies may have different ledgers for different purposes, but financial transactions typically start by recording them in a ledger.

DLT is a ledger that is recorded digitally (on the computer) and shared among the parties involved in a given transaction. It is also called a "distributed database of records" (Stagnaro, 2018). With certain control of security, the ledger becomes more transparent to all (and only) the parties involved (Baliga, 2017). The shared ledger provides more compatibility than separate ledgers. In separate ledgers, participants have their own systems which may not be compatible with the others which increases the possibility of human error or fraud (Tapscott \& Tapscott, 2017a).

\section{Interoperability}

Webster's dictionary defined interoperability (Interoperability, n.d.) as "the ability of a system to work with or use the parts or equipment of another system" (para. 1). Webster's definition focuses on equipment and parts and does not talk about systems. Interoperability in Information Technology (IT) field refers to the basic ability of computerized systems to connect and communicate with one another readily, even if they were developed by widely different manufacturers in different industries.

Data interoperability is of concern when multiple parties or multiple systems are involved in a given transaction or event (i.e. from system A to system B). The question that repeats itself often within these transactions could be: is the data from system A interoperable with system B. Lack of interoperability creates problems in communicating the data and therefore with the completion of the intended tasks. Furthermore, lack of interoperability among systems creates additional problems, like security problems, time and money waste and lost trust among the parties involved.

Blockchain has complete interoperability among the parties who use their systems (Stagnaro, 2018). Using the DLT, multiple parties who are working on the same transaction do not have issues with interoperability as it will have the parties post to one ledger and thus all parties can communicate with each other without having interoperability or compatibility problems. 


\section{The Block}

The block is a record of not only financial transactions but also anything related to the given transaction (Tapscott, 2018). It is called by other names including "transaction block" (Stagnaro, 2018), "data sets" and "data blocks" (Nofer et al., 2017). It is called a "block" or a "set" because it references transactions data, digital events, and all related information recorded electronically in the DLT (Crosby et al., 2016). Given that it is recorded in the DLT, it means that the block of data is shared with all others who are involved in the transaction validation and consensus; and to record follow up blocks (Pilkington, 2016). Multiple blocks of data can be recorded in the DLT and they are sequenced as well as referenced. The first block in the DLT is called the "genesis block" (Nofer et al., 2017). All subsequent blocks reference their previous blocks and ultimately reference the genesis block.

\section{The Chain}

As each block of data is entered in the DLT and it will to be linked with existing blocks to enable retrieval of interlinked information (Crosby et al., 2016). The blocks of data are connected in what is called a "chain" or it can be called that the blocks of data are chained together (Stagnaro, 2018). Chaining multiple blocks of data together makes easier to retrieve as one unit together or as complete information.

\section{Public and Private Key}

The public key refers to the main key that is used by the customer to retrieve the data holistically (Rennock et al., 2018). It is used by the customer to retrieve data and to find all related information in the DLT. The private key refers to a key entered by the different parties as the transaction moves along the route of approval from one party to the next (Stagnaro, 2018). Both public and private keys are used to simplify data retrieval as well as to enhance security as data is recorded in the DLT. Through the public key, customer data can be retrieved, and basic data are recorded about the transactions. Through the private key, critical records of authentication and approvals are recorded. As the data continues from one block to the next, the private key is needed to approve the transactions from one step to the next. So, while some basic data can be retrieved through the public key, decision making about each step in the process is finalized through recording and knowledge of the private keys.

\section{Digital Signature}

As transactions are entered into the DLT, every transaction is verified and authenticated through a digital signature (Baliga, 2017). In other words, completing the block requires having a digital signature identifying the party responsible for entering the data block into the chain. The digital signature also serves the purpose of data security and data integrity.

\section{Consensus Model}

Crosby et al. (2016) noted that blockchain establishes a system of creating distributed consensus. In other words, the system will not move forward unless most of the parties agree to the authenticity of their blocks (Baliga, 2017; Pilkington, 2016). Likewise, Crosby et al. (2016) explain that each transaction recorded in the DLT is verified in by consensus of participants. 
This, in turn, provides a verifiable record of every single transaction ever made within a given process.

\section{Literature Review - Mortgage Lending Process}

This section explains briefly the mortgage lending process. It starts by explaining the meaning of mortgage lending and the steps involved in processing a mortgage application. It then discusses the problems that the process could generate. Last, this section elaborates on how blockchain architecture and the associated technologies could provide solutions to the problems.

\section{About Mortgage Lending}

Mortgage lending process refers to processing a mortgage application through a set of steps whereby a decision is attained to approve (lend the money) or disapprove (deny the loan) the application. Mortgage lending process starts with a potential property buyer submitting a mortgage application and ends with the lender's decision. It is a multi-step process and involves multiple parties in reaching the final decision. While specifics of the steps and their ordering may have some differences, most mortgage lending applications go through these distinct procedures (Blockchain Technology Lab, 2016; Renuart, 2004):

- Borrower(s): the person or persons completes an application for a loan with the intent to either buy a new property or refinance an existing home; and provides documents on request of the loan officer and loan processor.

- Loan Officer: interfaces with the borrower to provide rates and determines prequalification

- Loan Processor: starts collecting documents from the borrower to get the loan into underwriting, and initiates orders with other parties such as an appraiser.

- Underwriter: reviews borrower's creditworthiness, the property condition, and all documents related to the loan and provides approval/denial based on the mortgage company's underwriting guidelines

- Appraiser: typically, not affiliated with the mortgage company, appraises the value of the subject property

- Property Inspector: hired by the borrower to inspect the subject property for defects or damages to assess required repairs prior to closing

- Title Agent: provides title insurance and acts as the escrow agent that facilitates the final closing of the loan, transfers funds, etc.

\section{Problems with Mortgage Lending Systems}

An important point that can be noted from the list above is the multiple intermediaries (or third parties) that mortgage application goes through. Brodersen et al. (2016) suggested that under systems like this, records of data are distributed across multiple parties involved in this common transaction. Tapscott and Tapscott (2017) noted that this kind of work that involves intermediaries is often rife with problems resulting in inefficient work that is liable to cause the following problems:

- Adding cost through fees and delays 
- Creating redundant through and onerous paperwork

- Opening up opportunities for fraud and crime

Nofer et al. (2017) further noted that when too many interrelated systems are involved, data integrity and consistency may be jeopardized and therefore is liable to affect the trust among the parties involved. The Blockchain Technology Lab (2018); suggested that in systems like this, the trust may be compromised, and it is likely that consensus will not be reached on a system with multiple parties. Udokwu (2018) noted that some of these systems with multiple collaborating parties are not interoperable and are subject to security vulnerabilities.

\section{Blockchain Remedies}

Blockchain solves these problems associated with the mortgage lending application:

- Interoperability

- The trust relationship among involved parties

- Security levels in transactions

Blockchain technology enforces interoperability across the multiple steps involved in the mortgage lending process. To begin with, blockchain technology cuts out the middleman (Underwood, 2018) which is one of the main sources of lack of interoperability. de la Rosa et al. (2017) noted that blockchain "allows for instant, decentralized, and secure transactions, for which there is no need for intermediaries" (p. 2). Besides, blockchain uses the DLT as a centralized repository for data following one set of standards and data formats. All parties involved in the mortgage application record and update data to the same ledger, thus there will no issues with data compatibility. All data entered can be read and understood by all parties involved and thus alleviating interoperability issues with data or otherwise.

Blockchain increases the level of trust among the parties involved. As each transaction is recorded in the DLT that is secured with a digital signature and there needs to be a consensus before the transaction is approved. Moreover, according to the essence of work in blockchain involves three steps: validate entries, safeguard entries and preserve historical records, thus increasing the level of trust among all parties involved (Crosby et al., 2016).

In blockchain, security can be enhanced through the consensus mechanism (Baliga, 2017) and through the use of public and private keys in the mortgage lending transactions (Pilkington, 2018). Through the consensus model, all parties involved in the mortgage lending application must sign on using the digital signature before it moves forward (Nofer et al., 2017). The use of private keys further ensures security to the data. Each given party in the mortgage lending process uses a private key and uses it when updating the DLT. This secures the data further because any attempt to hack the data must know the private keys of the multiple parties involved - a task that is harder than hacking a system that has only one set of security mechanism. Furthermore, Bordersen et al. (2017) noted that blockchain technology addresses many of the issues regarding data integrity and creates a robust audit trail for transactions for all parties involved. This increases the level of security as data are recorded when it goes across the multiple parties involved in the mortgage lending application. 


\section{Discussion - Blockchain and Mortgage Origination}

This section explains the combination of mortgage applications along with the use of blockchain technology to derive the conclusion that this paper sought from the beginning. Due to the complexity of blockchain technology, we will cover the technology from the point of view of the DLT. In other words, we will explain what happens in the DLT when each step in the process is completed and what transaction will be recorded to the DLT. While we explain the steps from the people and the process involved, we will limit the technology construct to only the DLT to make it more manageable.

\section{Step 1: Borrower Submits the Loan Application}

Distributed ledger transaction is created for the applicant. A record of 208 fields is created to enter data about the application. Nofer et al. (2017) call this the "genesis block".

\section{Step 2: Pre-Qualification of Loan}

Checking borrower information, DLT is updated with borrower information and decision is made to pre-approve the mortgage. A note to be made here is that pre-approval does not guarantee final approval of loan as final approval is contingent on other additional factors as will be explained later in this section. DLT is updated with the decision made and the digital signature of the authority who made the decision.

\section{Step 3: Loan Processing}

Supporting documents collected from the borrower and other borrower information is added in DLT. The supporting document could include credit history, proof of ability to pay the mortgage payment, employment record, prior years earning, debt/earning ration and other information. All information is entered in the DLT and secured through public and private keys.

\section{Step 4: Loan Underwriting}

Review of all documents, checking underwriting guidelines and recording in DLT. This step works as a validating process as the underwriter validates the submitted document and records the findings in the DLT.

\section{Step 5: Property Appraisal}

Information sent to the appraiser, appraiser estimates the value of the house, creates appraisal block in the DLT. The appraisal often includes comparison with other similar properties and the valuation decision.

\section{Step 6: Property Inspector}

The building inspector inspects house and record information in a block in DLT. The inspection checks the house for any damages that may affect the value of the house. The intent at this step is to grant a mortgage amount that is consistent with the value of the house. Notes from the inspector included and all information recorded for the property inspector record in the DLT. 


\section{Step 7: Loan Approval and Funding}

This is the final step in the mortgage lending process and at this point, a decision is made and if approved the funding for the mortgage is granted. The decision is made after all involved parties complete their transactions, record them in the DLT and approve them with their digital signature. Both public key and private keys are used and are reflective of the development, thus the consensus model is applied here in the mortgage lending application process.

\section{Conclusion}

Based on all the discussion above, we list below in Figure 3 the model for mortgage lending applications when using blockchain technology. The model is based on the organizational framework that we selected which involves three constructs: people, process and technology involved in mortgage lending application process. The people construct in Figure 3 lists the people (job titles) who are involved in the mortgage lending process. The second construct of process list the processes (or steps) that the mortgage application goes through under the blockchain architecture. The third construct shown in the figure lists the technological changes that take place in the DLT after the completion of each step in the mortgage lending processing.

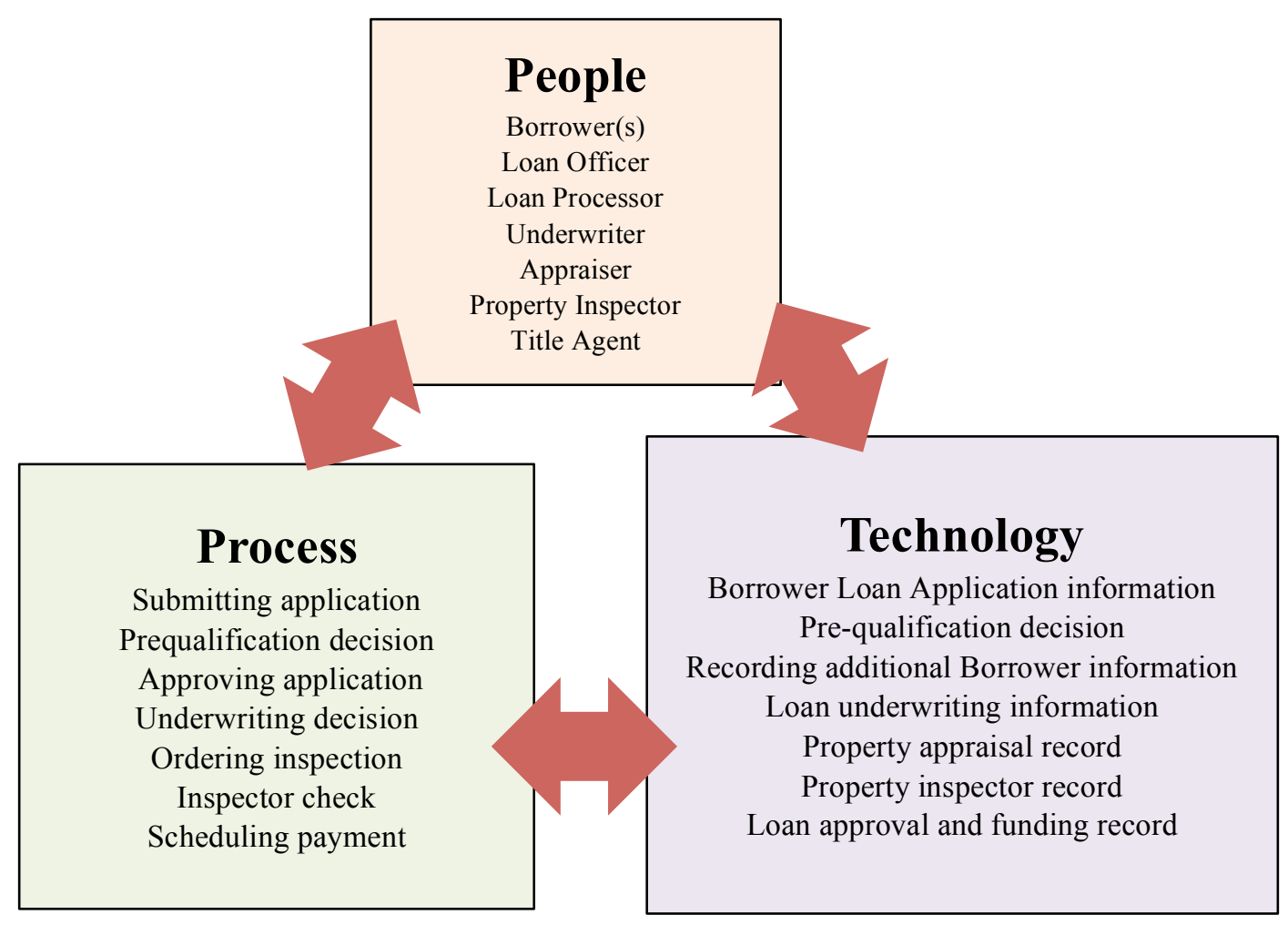

Figure 3. The model for Mortgage Lending and Blockchain 


\section{References}

Baliga, A. (2017). Understanding blockchain consensus models. Persistent.

Biggs, J., Hinish, S. R., Natale, M. A., \& Patronick, M. (2017). Blockchain: Revolutionizing the global supply chain by building trust and transparency. New Brunswick, NJ: Rutgers University.

Blockchain Technology Lab (2018). Why Blockchain can optimize the loan origination process. Blockchain Technology Labs.

Brodersen, C., Kalis, B., Leong, C., Mitchell, E., Pupo, E., \& Truscott, A. (2016). Blockchain: Securing a new health interoperability experience. Accenture. Retrieved from https://www.healthit.gov/sites/default/files/2-49-accenture_onc_blockchain_challenge response august8 final.pdf

Crosby, M., Nachiappan, Pattanayak, P., Verma, S., Kalyanaraman, V. (2016). BlockChain technology: Beyond Bitcoin. Applied Innovation Review, 2, 6-19.

Chen, I. J., \& Popovich, K. (2003). Understanding customer relationship management (CRM): People, process and technology. Business Process Management Journal, 9(5), 672-688.

de la Rosa, J. L., Torres-Padrosa, V., el-Fakdi, A., Gibovic, D., Hornyák, O., Maicher, L., \& Miralles, F. (2017). A survey of blockchain technologies for open innovation. Proceedings of 4th Annual World Open Innovation Conf. WOIC (pp. 14-15), San Francisco, CA, USA.

Fanning, K., \& Centers, D. P. (2016). Blockchain and its coming impact on financial services. Journal of Corporate Accounting \& Finance, 27(5), 53-57.

Hutchison, D. (2012). Accounting practices and earnings volatility in mortgage banking. Journal of Housing Research, 21(2), 139-158.

Interoperability (n.d.) In Merriam-Webster.com. Retrieved from http:/www.merriamwebster.com/dictionary/interoperability

Nofer, M., Gomber, P., Hinz, O., \& Schiereck, D. (2017). Blockchain. Business \& Information Systems Engineering 59(3), 183-187.

Pilkington, M. (2016). Blockchain technology: Principles and applications. In F. Olleros, \& M. Zhegu (eds.), Research Handbook on Digital Transformations. Cheltenham, UK: Edward Elgar.

Pieroni, A., Scarpato, N., Di Nunzio, L., Fallucchi, F., \& Raso, M. (2018). Smarter city: Smart energy grid based on blockchain technology. International Journal on Advanced Science, Engineering and Information Technology, 8(1), 298-306.

Porru, S., Pinna, A., Marchesi, M., \& Tonelli, R. (2017). Blockchain-oriented software engineering: Challenges and new directions. Proceedings of the 39th International Conference on Software Engineering Companion. Buenos Aires, Argentina (pp. 169171). 
Renuart, E. (2004). An overview of the predatory mortgage lending process. Housing Policy Debate, 15(3), 467-502.

Rennock, M., Cohn, A., \& Butcher, J. R. (2018). Blockchain technology and regulatory investigations. The Journal of Litigation, 35-44.

Roehrs, A., da Costa, C. A., da Rosa Righi, R., da Silva, V. F., Goldim, J. R., \& Schmidt, D. C. (2019). Analyzing the performance of a blockchain-based personal health record implementation. Journal of biomedical informatics, 92, 103-140.

Shirani, A. (2018). Blockchain for global maritime logistics. Issues in Information Systems. 19(3) 175-183.

Smith, K., \& Dhillon, G. (2017). Blockchain for digital crime prevention: The case of health informatics. Proceedings of the $33^{\text {rd }}$ American Conference on Information System, Boston, $M A$.

Stair, R. M., \& Reynolds, G. W. (2016). Fundamentals of information systems ( $9^{\text {th }}$ ed.). Boston, MA: Cengage Learning.

Stagnaro, C. (2018). White paper: Innovative blockchain uses in health care. Freed Associates (pp. 1-10).

Tapscott, D., \& Tapscott, A. (2016). Blockchain revolution: How the technology behind bitcoin is changing money, business, and the world. Toronto, Canada: Penguin.

Tapscott, A., \& Tapscott, D. (2017a). How blockchain is changing finance. Harvard Business Review, 2-5.

Tapscott, D. \& Tapscott, A. (2017b). The blockchain revolution \& higher education. Educase Review, 10-24.

Tapscott, D. (2018). Blockchain revolution: The Internet of value. Insight Investment.

Underwood, S. (2016). Blockchain beyond Bitcoin. Communication of the ACM, 59 (11), 15-17.

Udokwu, C. (2018, June). Securing cross-organizational business process with blockchain enabled smart contract. Technical Report, 1-11.

\section{Authors' Biographies}

Azad Ali, D.Sc., Professor of Information Technology at Eberly College of Business - Indiana University of Pennsylvania has 34 years of combined experience in areas of financial and information systems. He holds a bachelor's degree in business administration from the University of Baghdad, an M.B.A. from Indiana University of Pennsylvania, an M.P.A. from the University of Pittsburgh, and a Doctorate of Science in Communications and Information Systems from Robert Morris University. Dr. Ali's research interests include service learning projects, web design tools, dealing with isolation in doctoral programs, and curriculum.

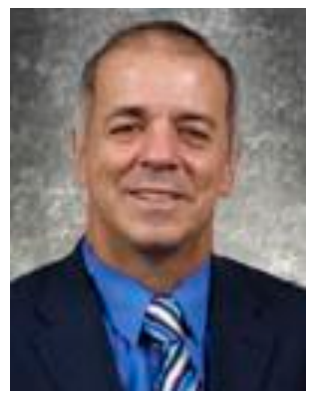


David T. Smith, Ph.D., Professor of Computer Science - Indiana University of Pennsylvania has 18 years' experience in academia and 21 years of industry experience in database systems, computer language development, and other systems programming. He holds a bachelor degree in Physics and Mathematics Education from Indiana University of Pennsylvania, an M.S. in Computer Science from University of Central Florida, and a Ph.D. in Computer Science from Nova Southeastern University. Dr. Smith is active in consultancy and has research interests in artificial intelligence, distributed object computing, data mining, and software engineering.

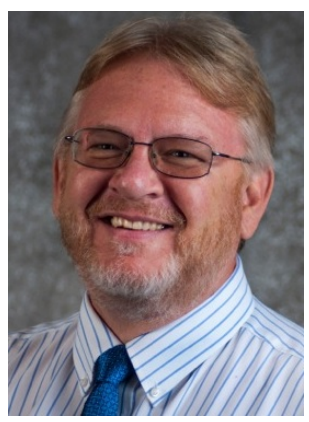

